\title{
Views on School Violence by Stakeholders of Four Schools in Nkangala District of Education, South Africa
}

\author{
Soane Joyce Mohapi \\ Centre for Continuous Professional Teacher and Community Education and Training \\ UNISA College of Education, South Africa
}

Doi:10.5901/mjss.2014.v5n1p263

\section{Abstract}

The increase of violence in South African schools puts school managers under enormous amount of pressure of ensuring the safety of learners under their care. This paper used mixed methods. Data were collected through questionnaires and semistructured interviews. The study reviewed findings of the bigger project that investigated the dynamic of violence in South African schools, with the view of exploring views of stakeholders regarding school violence. The paper argued that the measures to curb violence would work best when they are generated not only by school staff, but also by parents, representatives from community organizations and learners. School managers therefore cannot win the battle of school violence alone; they would need the involvement of all the stakeholders to ensure that schools are safe environments where learners can receive a high quality education without fear. The study concluded by suggesting measures that school can be used to curb school violence.

Keywords: School managers' role, learners' safety, South African Schools' Act

\section{Introduction and Background}

This study is as results of research project conducted in six provincial education departments in South Africa on the dynamic of violence in schools. Mncube and Harber cited the following objectives for the project:

- Comparing perceptions, experiences and incidences across the provinces.

- Categorising the types of violence that occur in South African schools both in terms of the nature of violence and the actors involved.

- Investigating the extent to which violence is a barrier to learning. (2013: 28).

Based on the findings of this research project, the researcher saw the need of investigating the views of stakeholders regarding putting measures to deter school violence. Violence in South African schools remains a challenge. Continuously media reports on violence happening in South African schools warrants more research. According to statistics published by the South African Institute of Race Relations (SAIRR), South African schools are the most dangerous in the world. This report followed recent media reports of shootings, stabbings, rapes, and robberies in South African schools. (Mail guardian, 26 April 2013). The survey conducted by SAIRR suggests that only $23 \%$ of South African pupils said they felt safe at school. The study by the South African Human Rights Commission (SAHRC) reported that one in five learners $(21 \%)$ had been threatened or hurt by someone at school, and a third (33\%) had been verbally abused by someone at school. The Eye Witness News (01 March 2012) reported that a 16 year old boy was killed at secondary school in Valhalla Park.(2013: 1)

School violence is worldwide concern, Susko et al (2003), in the article "Poverty and school violence", believe that violence in schools and neighborhood are directly related, violence according to them is caused by socio economic status and other factors like ethnicity. They further mentioned that in New York school violence is affected by block gangs. They found people from low income neighborhood separated from high and middle class citizens. It was clear from their study that school violence is dependent on not only the school environment but also the neighborhood influences. This study aimed at exploring views of stakeholders of four schools in Nkangala education district on school violence and their role in putting measures in place to deal with it. and have knowledge of factors that cause school violence; poverty, domestic violence; which emanate from neighborhood problems. Learners and teachers in this study mentioned that they are aware of drug use and all the drug dealers in their neighborhood. Learners are daily exposed to these drug dealers who are on the street corners, certain learners are tempted or forced to become drug dealers on their behalf. This implies learners cannot feel safe when walking around their own neighborhood. 
In another study conducted by Bryan et al (2009), Anderson and Anderson (1996), as they hypothesize find culture of honor associated with school violence. The study suggested that the apparent relationship between general acts of violence and the culture of honor in the USA might be at least partially explained by demographic differences between Southern and Western states. Knowledge of how the culture of honor play role in school violence could assist school managers to develop measures to curb school violence by identifying learners at risk and understand how to address unique violence issues affecting their schools.

This paper has six sections, in section one the paper outlined background and introduction to the study, section two dealt with research aims, research problem, research question and significant of the paper, theoretical frame work is mentioned in section three, literature is reviewed in section four, section five outlined methods used in the study, sampling procedure, collection of data and data analysis. Section six included findings of the study, discussions, recommendation, conclusions and acknowledgement

\section{Research Aims}

In relation to the bigger project conducted on the dynamics of violence as mentioned above, this paper aimed at:

- Finding out the views of learners, teachers, school staff, school management team and school governing bodies on school violence

- Identifying common types of violence occurring in the four schools in Nkangala district of education

- Identifying and suggest measures and initiatives that the four schools in Nkangala district may use to curb school violence.

\section{Research Problem}

Safety and security in schools is a priority for the learners to learn without fear. Violence in South African schools is a major challenge for stakeholders in education. The study conducted by Rossouw (2008), revealed that teachers have been subjected to physical and psychological violence in South African schools. In one of the schools in KwaZulu Natal, the deputy principal was beaten by the principal while performing his duty, this sent a wrong signal to teachers and learners, and they felt unsafe because they regarded their managers as custodian of policies that deals with safety and violence in schools,

\section{Research Question}

In an attempt to address the problem mentioned in this paper, the following question needed to be answered.

What measures and initiatives are taken by stakeholders in four schools in Nkangala education district to promote a secured environment for teaching and learning?

\section{Significance of the Study}

The study used learners, parents, teachers, school governing body members in gathering information on issues of school violence. Little was said about the role of stakeholders in curbing violence in schools in the report on dynamics of school violence (Mncube and Harber, 2013), this study so a need of exploring further the role views of stakeholders and their role in putting measures in place to deter school violence. The paper concluded by suggesting measures that may be of help South African schools' stakeholders to curb violence in their schools.

\section{Theoretical Framework}

The theory that underpinned this paper is social learning theory. According to social learning theorists there is strong relationship between social learning concepts and deviant behaviours (Arriaga and Foshee, 2004). Of these social learning concepts, differential association has been examined most frequently and has consistently been shown to be a significant factor in explaining criminal and deviant behaviours (Clingempeel and Henggeler, 2003; Daigle et al., 2007; Haynie et al,. 2006). It is worth noting that this paper relates to behaviour such as bully by learners, drug use and other violent and non-violent deviant behaviour. Social learning variables have been found to explain these aforementioned behaviours in numerous studies (Akers and Silverman, 2004; Akers et al., Barak, 2004). Association with family and the 
impact on behaviour.

\subsection{The Role of Family}

The research literature has consistently found that there is a strong relationship between childhood experiences of violence in the family and early childhood aggression, and a more moderate relationship between these experiences and adolescent aggression. Gover, Unnever and Agnew (2006) and Work by Hotton (2003) looked at childhood aggression and exposure to violence in the home. They found that childhood aggression and exposure to violence in the home was significantly related to aggressive behaviour among children. The study also revealed that hostile and ineffective parenting practices were related to higher levels of child aggression. Interestingly, it is noted in this study that parents seem not be unable to correct their children deviant behaviour, instead they refer them to the schools. One parent demanded that teachers should use corporal punishment to curb violence in schools.

\subsection{The Role of Peers}

Peer influences appear to be more important in adolescence. Research on adolescent aggression has shown that exposure to violent or delinquent peers, over and above the influence of family, are stronger predictors of violence among adolescents. It was noted in one of the schools that learners who are bully are boys, especially those who are from initiation schools, they do not respect teachers, especially females and male teachers who are not from initiation school, as such boys see initiation schools as passport of being bully and disrespectful. Arriaga and Foshee (2004), in a study of intimate violence, examined the relationship between dating violence and friends involved in or supportive of this type of violence and inter-parental violence. The study found that while both variables were significant predictors, the effect of friend dating violence on the dating behaviours of adolescents was stronger than the effect of inter-parental violence. This finding is consistent with other research that indicates the power of peer influences on behaviour during adolescence (Herrenkohl et al., 2003). This finding has also been shown to be consistent when looking at aggression across gender. Daigle et al. (2007) examined gender differences in the predictors of juvenile delinquency.

\subsection{Policy Implication}

From a social learning perspective, deviant behaviour is learned and sustained via associations with family and peer networks. If one agrees that this is the source of such behaviour, and then it follows that these behaviours could be modified "to the extent that one is able to manipulate those same processes or the environmental contingencies that impinge on them" (Akers and Sellers, 2004: 101). From this perspective, policy-makers should focus on developing and implementing preventive and rehabilitative programs that use social learning variables to change behaviour in a positive direction. School management and governors may use programs guided by social learning principles which include mentoring, behavioural modification, delinquency prevention, peer counseling and use policies dealing with school discipline. The idea behind some of these types of programs is that providing positive experiences and role models for young people serves to expose them to conventional norms and values that might diminish future violence acts. The social learning theory mentioned above helped to understand school violence better.

\section{Literature Review on School Violence}

The researcher reviewed literature to gather information about school violence; this includes legal documents, school violence and discipline.

\subsection{Legal documents}

Chapter 2 of the Constitution of 1996, the Bill of Rights contains various rights that are applied to safe environment. The purpose of any school is to ensure that effective teaching and learning take place. Stakeholders within schools have an important task towards the safety learners. South African Schools Act of 1996 no: 84, declares a safe environment as a prerequisite of learning by making the following provisions:

Section 10 prohibits the use of corporal punishment, section 8 (1), places an obligation on school governing bodies to draw up Code of Conduct for learners, section 8 (2) stipulates that the schools code of conduct must be aimed at 
establishing purposeful and disciplined school environment. Section 8 (4), places a legal obligation on learners to comply with the code of conduct. In terms of these provisions education as a legal entitlement, should take place in an environment free of violence. Section 24 of the Bill of Rights of 1996 Act 108, implies to teachers and learners. Teachers should teach freely. It is the legal duty of school managers to provide sufficient supervision and to safe guard learners (Netshitashane \& Van Vollenhoven, 2002, 19).

School managers in this study confessed that policies to managed school violence are available but parents are not cooperating in implementing them, learners on the other mentioned that they are not happy by the manner in which principals address school violence problems in their schools

\subsection{School violence and discipline}

Since 1995 in South Africa, there has been a notable decline in learners discipline manifesting in such incidents as: drugs and alcohol abuse, bully learners, fighting, physical and verbal abuse and these made teaching a daunting task for teachers. School discipline and education are inextricably tied to one another because the one cannot exist without the other. In schools where discipline is a problem, the culture of teaching and learning tends to move into a downward spiral (Lorgat, 2008). Classroom disruption is a major impediment to learning. Studies conducted in South Africa on school discipline, indicate that learners discipline lies at the very heart of a culture of teaching (Phatlane 2001 88). Many studies on school discipline approach the problem from an almost "fix-the-kids" approach (Walsh, 199). It is the assumption of this paper that school violence is not a one man show, all role players must participate in making schools free from violent behaviour. South African School Act of 1996, abolished corporal punishment in South African schools, but we still hear the use of punitive measures in ensuring discipline in schools, in certain schools principals are the one administering the punishment. Principals are implementers of policies, by virtue of their position they must provide direction and advice.

In South Africa there are parents who promote the use of corporal punishment in schools. According to Mohapi, 2007, is evident that the use of corporal punishment is rife in schools serving black communities According to (Netshitahame \& Van Vollenhoven 2002, to ensure effecting teaching and learning in every school, safety of both learners and teachers should be managed and interwoven with all routine of school administration functions. Violence in schools goes hand in glove with discipline problems; as such any discussion dealing with violence in schools will incorporate learner discipline.

\section{Research Methods}

The study used mixed methods; both principles of the qualitative and quantitative research were used to generate the data. Qualitative researchers believe that the task of a qualitative researcher is to acquire insight and develop understanding by the researcher getting close to the data in order to understand participants' point of view and to obtain social knowledge (Clarke, 1999), meaning that it is the responsibility of the researcher to make sense of the data provided by participants.

\subsection{Description of the sample}

According to Ary et al. $(1996,437)$, the main consideration when deciding on sample size is the degree of accuracy one wants to achieve in the estimation of population. Eight participants were selected from each of the four schools selected purposefully by the District Director of Nkangala region in Mpumalanga province in South Africa. These schools posed challenges to the region with number of violence cases reported to the provincial education department and the South African Police Services (SAPS).

\subsection{Sampling procedure}

The sample comprised two learners in grade seven. The researcher used Individual interviews with learners who have been affected by violence and those who have perpetrated violence. Two teachers were also used for individual interviews, the principal and life orientation teacher, two non-teaching staff and two members of school governing bodies. 


\subsection{Data collection}

The paper used both semi structured interviews and questionnaires to collect qualitative and quantitative data.

\subsection{Semi structured interviews}

Individual semi structured interviews were conducted with 8 learners (two from each school), 8 teachers ( 4 principals and 4 Life orientation teachers), 8 School governing bodies and 8 non- teaching staff. A total of 32 participants participated in the interviews.

\subsection{Questionnaires}

All participants who were interviews completed the questionnaire, each category of participants had their own questions

\subsection{Ethical consideration}

A number of ethical issues were considered:

- Confidentiality, anonymity and privacy were respected.

- Consent of all participants were sought:

- The researcher outlined the aim and purpose of the research to all participants

- Feedback to participants was provided, both to verify data used for analysis and to comment on interpretation.

\section{Data Analysis}

Quantitative data was analyzed using descriptive statistics. Data collected through semi structured interviews involved categorizing, synthesizing and searching for patterns in the data collected (Patton 1990: 202). Data were grouped in order to derive meaningful patterns . Focus was also on the four questions associated with qualitative data; "What I observed and noticed; why I noticed what I noticed; and how I interpreted what I noticed; how I knew that my interpretation was right one" (Holloway \& Jefferson 2000: 55). Quantitative data was analyzed using graphs. Documents relating to school safety, discipline and security were checked and compared the findings with data collected through questionnaires and individual interviews

\subsection{Semistructured interviews}

The following themes emerged from the interviews:

- Common types of violent behavior in the four schools

- The impact of violence on teaching and learning

- School violence and school discipline

- Measures put in place to deal with violence in schools

\section{Research Findings and Discussion}

In terms of South African Schools' Act (SASA) stakeholders in education guided by school managers and school governing bodies should develop policies that will assists in curbing violence in schools, the following were common violent behavior in all the fours the schools

\subsection{Use of drugs}

in all four schools participants mentioned the use of drugs as a cause of school violence. One of the teachers interviewed in this study mentioned that "Nyaope" is commonly used among learners. Especially in schools in their area, he said

"After break learners start behaving unbecomingly, because they have one hour of lunch to eat and use the drug", 
The use of dagga was reported as common in both girls and boys. One school governing body member (SGB) of school $B$, mentioned that there were boys who were selling dagga in the schools and they were suspended for a week and they came back to schools. According to her they were supposed to be expelled and go to prison.

"The matter was reported to the policies but nothing was done," said the parent. The parent was worried and said their children were not safe at school.

\subsection{Bullying}

It became apparent when interviewing learners and teachers that all four schools were characterized by boys who are bully. Initiation within Ndebele culture is respected. Often boys who come from the initiation school disrespect teachers; this was said by three teachers.

"Most of the boys after initiation schools see themselves as men and start becoming disrespectful to teachers", said one female teacher. According to this teacher, bully boys do not do their home works.

Violence in schools may be thought of only in terms of it being directed to learners; in this study it became apparent that teachers become the victims. One teacher indicated that during trips boys become drunk when calling them to order they start harassing female teachers.

\subsection{The impact of violence on teaching and learning}

In all four schools learners, parents and teachers indicated that violence is affecting teaching and learning, because when learners fight in class or when one learner become bully, the teacher decide to abandon the class, and the whole class miss the lesson because of the incident. Learners and teachers feel insecure; teachers are not free to teach inside the classroom. The teacher cannot manage discipline in his class and the lesson is disrupted.

One teacher said:

"As a teacher You feel small, you feel as if you are not at the right place and you ask yourself why did I follow this kind of a career".

One teacher explained that one day the violence inside the classroom happened in front of newly employed teachers, the teacher was scared.

It is evident from the responses above that a lot of teaching time is wasted on violence behaviour, because teachers will stop teaching and address the situation. Violence hinders learning, in most cases classes are disrupted, teachers spent quality time trying to calm down the situation. The findings in this paper indicate that violence, in most circumstances affects teaching and learning. Learners who do not do their home works, who become late, when reprimanded they become noisy and bully, when chased out of the classroom to go and do his work they refuse, as a results the teacher decide to leave the classroom unattended. Innocent learners who want to learn suffer. One learner indicated that she feel unsafe in the classroom, because if the teacher is not in the classroom, boys harassed them especially if you always do your work.

One learner said

"I don't feel safe at all in the school, because boys call you by names you do not like, they belittle you. If you score high marks they say you think you are clever"

Another learner also explained her ordeal by saying;

"A boy learner in her class told her (a girl learner) not to sit next to him ever again, because, she was a short "little Sotho girl"

The girl learner explain her experience as follows: "I do not know where to sit because I like sitting in front so that I can see on the chalkboard, now I do not how will I learn?"

From what these learners are saying it seems violent behaviour affect learners' learning and teachers teaching.

\subsection{School violence and school discipline}

South African school Act of 1996, no: 84 abolished corporal punishment in South African schools, yet it still being used in 
certain schools. During the interviews of one SGB member emotions were high; she was very concerned and said:

"Learners do as they please; they drop out of school and come back again when they are bored at home and this affect school discipline, teachers are afraid to discipline learners, principal must use corporal punishment"

One SGB member also said

"The school call parents, they don't want to come, parents also need education because if parents are not aware of what is happening at school and they are not aware that they can also play a vital role to the better future of their children, they will not come when called at school"

From the interviews held with school governing bodies it seems they suggest that parental involvement could assist in helping schools to address the school violence, what was clear also is that parent should be educated on the value of education.

\subsection{Measures put in place to deal with violence in school}

The national department of education introduced alternative to corporal punishment and many policies for example code of conduct of learners, safety policies and many more. These school policies and codes of conduct for learners amongst other things are meant to inhibit the use of drugs or any intoxicating substance, carrying of weapons or any sharp objects, using violent or vulgar language and making threats and help the schools to manage school discipline. Despite the existence of these policies corporal punishment, violence, physical and sexual abuse and gang related activities are still the order of the day in many South African schools. Principals who were interviewed mentioned the existence of safety and security committees in their schools. These committees include mainly parents, with few teachers and learners. One principal said:

"In every class there is a monitor who continuously has to report about misbehavior on weekly basis but at certain point, they become victims at such they do not report the cases"

During the interviews with school governing bodies, it became apparent that in the four schools parents are not involved in schools' affairs, when called they do not come. It calls upon school managers to explore possibilities of educating their school governing bodies about school violence and how it affects teaching and learning. School managers should take school governing bodies and parents on board regarding policies they can use to eradicate violent behavior.

This study explored the problem in one province in South Africa and measures put in place to deal with violence in schools and find out if the situation can be improved. Every principal is aware of disciplinary procedures that can be used to reprimand learners who misbehave

Two principals confirmed and said:

"We are having a disciplinary committee in our school which informs us on how to handle problematic children. Usually before a learner can be charged or found guilty, he she appear in front of disciplinary committee"

Despite this knowledge of policies, violent still occur within school premises.

Teachers are also aware of the code of conduct. According to one teacher there is a code of conduct which involves parent, learner, teacher and the department of education. She said:

\section{"Parents do not assist us to implement the code of conduct"}

Her frustration is that parents know what time is the school is starting; if their children are late they do not bother to encourage them to be early at school. From what the teacher is saying, is that although there are policies parents do not play their role in helping the school to implement them.

One support staff said:

Teachers blame, parents for non involvement in education and but parents are not taken on board regarding their role, they do not have a clear meaning of education, some of the parents they do not know why their children at school" 
One learner had this to say regarding how she felt about school violence:

"Incidents of violence reported to school management, are not handled to my satisfactorily, this result in learners leaving school, especially girls".

On teacher in this study blame learners and said:

"Learners think that they are doing us a favor, parents do not bother to check children work, when you reprimand learners about their homework especially boys they march out of the class".

It is apparent from participants' responses that the school and parent community could work together to create a peaceful environment free from violence. Schools alone cannot function as a panacea for these problems (Furlong \& Morrison 1994: 147; Saunders, 1994: 3), therefore all role players should be involved, this include learners, teachers, non- teaching staff, school managers, parents and the community at large.

\section{Questionnaires}

\subsection{Victims of school violence}

\subsubsection{School A}

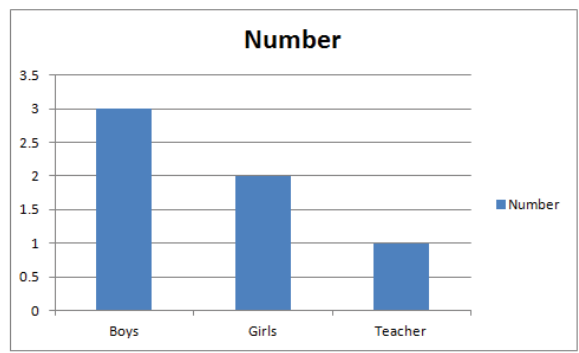

\subsubsection{School B}

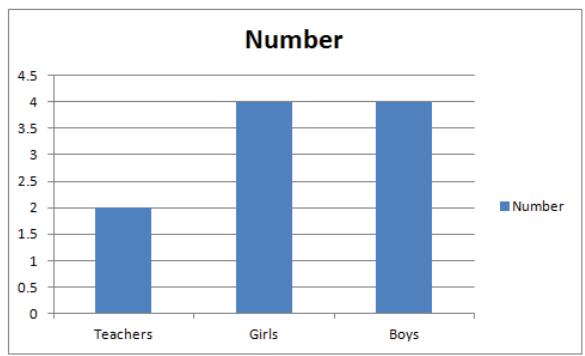

\subsubsection{School C}

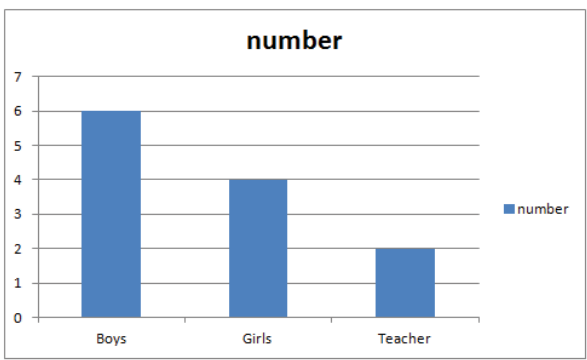




\subsubsection{School D}

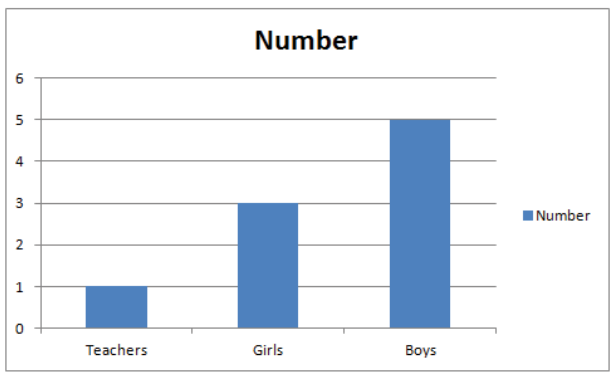

In school $\mathrm{C}$ number of boys who are victims of violence is higher than in the three schools, this could mean boys fighting against each others. In all the schools number of girls who are victims is less than five. Teachers as well according to the findings became victims of violence, this is as results of learners not doing their home work and when reprimanded, they become bully. Sometimes learners were late to school and to class and forced themselves into the classroom, as a result teaching and learning were disrupted.

\subsection{Frequency of violence}

\subsubsection{School A}

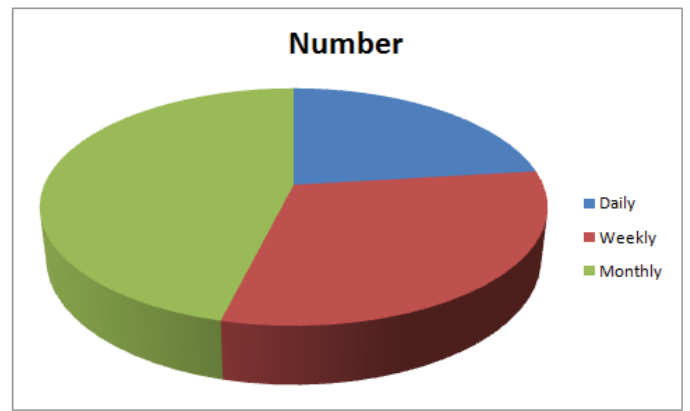

In terms of the frequency of violence in the four schools, in all the schools there were daily incidents of violence, sometimes not reported to school management, in all the schools on daily basis teachers deals with bully boys, especially after break. In all the schools monthly incidents are more than daily incidents

\subsubsection{School B}

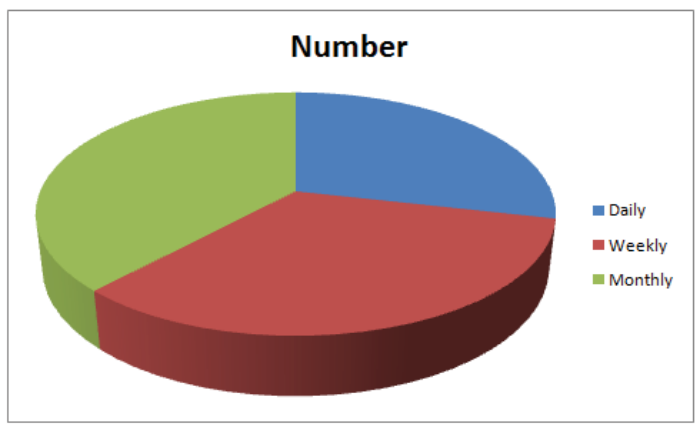




\subsubsection{School C}

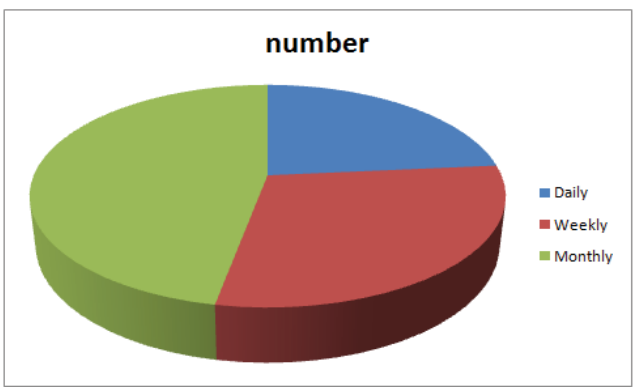

\subsubsection{School D}

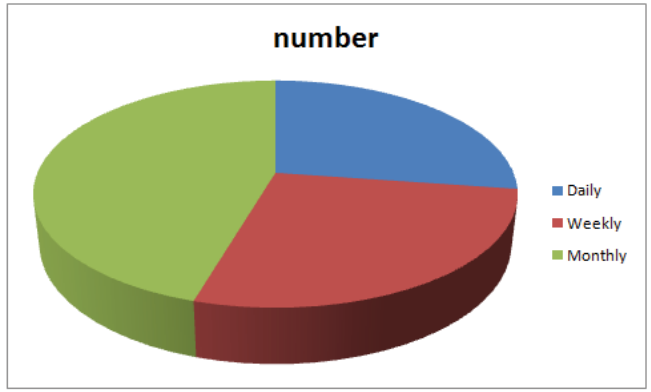

\subsection{Types of school violence}

From data collected it became clear that the use of drugs in school $\mathrm{C}$ was high. Regardless of different campaigns taking place in South Africa towards preventing violence against women, girls and children, during this study it became apparent that not only girls and young boys are still the victims of violence in the four schools but teachers as well. Common types of school violence in the three schools are drug usage, which is high in school, fighting is less than $50 \%$ but more than $40 \%$ in all three schools. Cases of bully learners in school A and D are less as compared to the two schools

\subsection{Incidents of use of drugs}

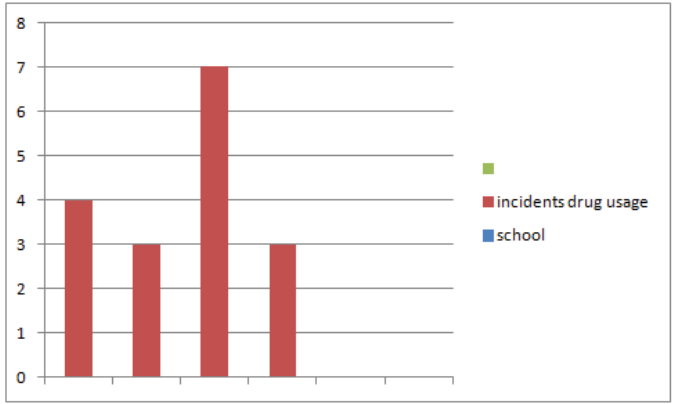

There are seven incidents of the use of drugs in school C, school B and D had three each, A had four incidents that recorded by the school manager 


\subsection{Number of cases report}

According to the findings during the time I conducted the study in school $\mathrm{C}$, seven cases of the use of drugs were reported to SAP, six and five incidents of fighting and bullying respectively were recorded and parents of affected learners were informed accordingly, this implies to school $D, A$ and $B$

\section{Discussion}

From the findings of the study it was clear that the community where the schools are located had huge role in the manner in which learners behaved at school, this relate with social learning theory where associations with the family, peer contributed to school violence. Taking an overview of the participants' responses, involvement of parents through representation of governing bodies and representation of learners through representative council of learners in curbing school violence, in all four schools safety committee was not functional, only one school conducted a disciplinary hearing of one boy who was carrying a gun at school, the boy was suspended, the challenge was the boy never came back to school and he was not expelled from school. I also noticed that in three schools all problematic learners were referred to the principals. I saw principal holding a stick in his hand, when asked if he is using it, he said it was only for making learners to respect the bell he will never use it. In this study both learners and teachers where affected by violence, especially during teaching and learning. At certain point that female teachers become the victims of violence, they were $t$ harassed by both boys and girls in the school

In all four schools performance of learners is not pleasing especially in the final examination, school violence could be contributing factor because there are sometimes disruption in classes that impact negatively on teaching and learning, both learners and teachers feel unsafe in a chaotic classroom.

The study further found that in all four schools violence is a challenge and a concern for parents teachers, learners, non-teaching staff community and school managers, and that school managers should put measures in place to deter use of drugs, carrying of weapons, bullying, fighting and any form of deviant behavior that might impact negatively on teaching and learning. This study concludes by discussing some of the measures that school managers can employ.

\section{Suggested Measures that School Managers can Use to Curb School Violence}

All principals of the four schools mentioned the existence of code of conduct of learners, South African School Act and safety and security committees in their schools, however teachers complaint about long procedure in dealing the perpetrators of school violence. It calls for the use these committees and policies more regularly and all deviant behavior should be dealt with immediately when it occurs

School violence is not a one man show, schools should use other community structures parents SAPS to address problem of violence in schools, firstly understanding the community where the school is situated and use stakeholders such as social workers, the churches, local municipality and community policing forum in making school safe place for learning.

Given school violence challenges in the four sample schools mentioned in the study, managers of the four schools may form support structures and forums where on monthly basis they discuss issues pertaining to violence in schools with the purpose of educating the community and empowering school governing bodies to take their rightful position in ensuring that schools are safe.

\section{Acknowledments}

I would like to acknowledge the following who contributed to the bigger project on dynamic of school violence:

Professor Vusi Mncube, University of South Africa and Honorary Professor university of KwaZulu Natal for leading the project.

Emeritus Professor Clive Harber University of Birmingham and Honorary professor: University of South Africa for editing the final report.

Dr. MC Maphalala; University of South Africa; for report refinement and alignment.

I acknowledge the four schools that participated in my study for take in part in the individual interviews and the completion of the questionnaire, not forgetting the Regional Director who gave us the permission to conduct the study. 


\section{References}

Akiba, M. 2008. Predictors of Student Fear of School violence: A comparative Study of eighth graders in 3 countries', School Effectiveness and School Improvement 19,1 pp51-72

Akers, R.L. and C.S. Sellers. 2004. Criminological Theories: Introduction, Evaluation, and Application (4th ed). Los Angeles: Roxbury Publishing.

Akers, R.L., and A.L. Silverman. 2004. Toward a Social Learning Model of Violence and Terrorism. In M. Zahn, H. Brownstein and Shelly Jackson (Eds.), Violence: From Theory to Research (pp. 19-35). Cincinnati: LexisNexis and Andersen Publishing.

Anderson, C.A. and Anderson, K.B. 1996. Violence crime rate studies in Philosophical context: A destructive testing approach to heat and southern culture of violence effects. Journal of personality and social psychology. 70-740-756

Arriaga, X. B. and Foshee. V.A. 2004. Adolescent dating violence: Do adolescents follow in their friends', or their parents', footsteps? Journal of Interpersonal Violence,19(2), 162-184.

Ary, D., Jacobs, L.C \& Razavier, A. 1996. Introduction to research in education. $5^{\text {th }}$ edition. Florida: Harcourt Brice College.

Bailey, K.A \& Ross, C.J 2001..School safety and youth violence. A Legal primer. Washington DC: Hamilton Fish Institute.

Barak, G. 2004. A Reciprocal Approach to Terrorism and Terrorist-like Behavior. In M.

Deflem (Ed.), Terrorism and Counter-Terrorism: Criminological Perspectives, Sociology of Crime, Law, and Deviance (pp. 33-49). Amsterdam: Elsevier

Brody, I.N., \& Vardin, P.A 1979. Children rights: Contemporary perspectives. New York: Teacher College Press

Bryan, P. , Lindsey, L. Osterrman, O and Collin, B. 2009. The school violence and the culture of honor. Psychology science. Research theory, application in psychology and related sciences. Volume 20 number 11 p 1400-1401

Clingempeel, W. G. and S.W. Henggeler. 2003.. Aggressive juvenile offenders transitioning into emerging adulthood: Factors discriminating persistors and desistors. American Journal of Orthopsychiatry, 73(3), 310-323.

Daigle, L.E., F.T. Cullen and J. Wright. 2007. Gender differences in the predictors of juvenile delinquency: Assessing the generalityspecificity debate. Youth Violence and Juvenile Justice, 5(3), 254-286.

Furlong, M.J \& Morrison, G.M. 1994. School Violence and Safety in perspectives. School Psychology Review, 32:139-150

Gover, Angela R. 2002. The effects of child maltreatment on violent offending among institutionalized youth. Violence and Victims,17(6), 655-68.

Hammett,D. and Staeheli,L. 2011. 'Respect and Responsibility : Teaching Citizenship in South African High Schools', International Journal of Educational Development 31, 3 pp269-276

Harber,C. (2004) Schooling As Violence : How Schools Harm Pupils and Societies (London:RoutledgeFalmer)

Haynie, D. L., E. Silver and B. Teasdale. 2006. Neighbourhood characteristics, peer networks, and adolescent violence. Journal of Quantitative Criminology, 22(2), 147-69.

Herrenkohl, T. 2003. Examining the link between child abuse and youth violence: An analysis of mediating mechanisms. Journal of Interpersonal Violence, 18(10), 1189-1208.

Hochstetler, A., H. Copes and M. DeLisi.2002. Differential association in group and solo offending. Journal of Criminal Justice, 30(6), $559-566$.

Hotton, Tina. 2003. Childhood Aggression and Exposure to Violence in the Home. Ottawa: Canadian Centre for Justice Statistics:

Holloway, W. \& Jefferson, T. 2000. Doing qualitative research differently, free association narrative \& the interviews methods. London: Sage publication

Lorgat, H. 2003. How to Beat Corporal Punishment. The Teacher's Voice 7 (7).

Mncube, V \& Harber, C. (2013)The Dynamic of violence in schools. University of South Africa: Pretoria

Netshitahame, N.E \& Van Vollenhoven, W.J 2002. School Safety in Rural Schools: Are schools as safe as you think they are? South African journal of Education 22(4) 313-318

Patton, M.Q. 1990. Qualitative evaluation and research methods. Newbury Park, London: Sage

Phatlane, R.S. 2001. The impact of the Abolition of Corporal Punishment on Disadvantaged Urban Secondary Schools'. M.Ed. dissertation. University of Pretoria

Saunders, S.C. 1994. Safe at School: Awareness and Action for parents and kids. Grade k-12. Minncapolia: Free Spirit.

Smit M.E. 2010. The Role of School Discipline in Combating Violence in Schools in the East London Region, unpublished Master of Eeducation at the University of Fort Hare, East London

Stevens, G., Wyngaard, G. \& Van Niekerk, A. 2001. The safe school model: An antidote to school violence. Perspective in Education, 19(2). 145-158

Republic of South Africa. 1996a. The Constitution of Republic of South Africa. Act No: 108 of 1996. Pretoria: Government Printer.

Republic of South Africa. 1996b. South African School Act No: 84 of 1996. Pretoria: Government Printer

Republic of South Africa. 1997. Abolition of Corporal Punishment Act No: 33 of 1997. Government Gazette, 18256, Sept 5

Walsh, K. (1991). Discipline for Character Development. Birmingham: REP Books 